\title{
The propagation of financial turbulence: interdependence, spillovers, and direct and indirect effects
}

\author{
Zhongbo Jing' • J. Paul Elhorst ${ }^{2}$ - Jan P. A. M. Jacobs ${ }^{2,3,4,5}$. \\ Jakob de Haan ${ }^{2,6,7}$
}

Received: 1 November 2016 / Accepted: 29 January 2017 / Published online: 3 April 2017 C The Author(s) 2017. This article is an open access publication

\begin{abstract}
We investigate the propagation of financial turbulence via trade, capital flows, and distance channels in the pre-crisis and Global Financial Crisis periods by modeling spillover and interdependence effects, using spatial econometric techniques. Financial turbulence is proxied by the ratio of nonperforming loans to total loans in a country. Spillover effects are defined as significant changes in the linkages between countries due to a shock, and interdependence effects as strong linkages among pairs of countries independent of shocks. Using annual data of 40 countries from 2003 to 2010, we find that interdependence and spillover effects should be jointly analyzed. Furthermore, our results suggest that the capital flows channel is more important than the other two channels in capturing propagation of financial turbulence. By deriv-
\end{abstract}

\begin{abstract}
We thank Haizhen Yang, Niels Hermes, and Tjeerd Boonman for helpful discussions, and two referees and the editor for their helpful comments on a previous version of the paper. Zhongbo Jing thanks the National Natural Science Foundation of China (NSFC Grant Numbers: 71532013, 71273257, 71401188, and 71503290) and CUFE Young Researcher Development Fund (QJJ1619) for support. The views expressed do not necessarily reflect those of De Nederlandsche Bank.
\end{abstract}

\footnotetext{
$凶$ J. Paul Elhorst

j.p.elhorst@rug.nl

1 School of Management Science and Engineering, Central University of Finance \& Economics, Beijing 100081, China

2 Faculty of Economics and Business, University of Groningen, PO Box 800, 9700 AV Groningen, The Netherlands

3 University of Tasmania, Hobart, Australia

4 CAMA, Australian National University, Canberra, Australia

5 CIRANO, Montréal, Canada

6 De Nederlandsche Bank, Amsterdam, The Netherlands

7 CESifo, Munich, Germany
} 
ing what is known in the spatial econometrics literature as direct and indirect effect estimates, we show that the marginal effects of macroeconomic variables (like GDP growth, inflation, and credit growth) on financial turbulence take different forms during a crisis than in tranquil periods.

Keywords Financial turbulence $\cdot$ Interdependence $\cdot$ Spillover effects $\cdot$ Spatial panel econometrics

JEL Classification C23 - G21 · F30

\section{Introduction}

The financial crisis in the USA of 2007/08 led to banking crises in more than 20 countries (Laeven and Valencia 2013). Different from earlier crises, the Global Financial Crisis (GFC) not only affected many countries but also did so within a short period of time. Both features have stimulated scholars to investigate the spread of financial turbulence (cf. Cetorelli and Goldberg 2010; Aloui et al. 2011; Forbes 2012).

Two mechanisms can explain financial turbulence propagation, namely spillover effects and interdependence. Forbes (2012) defines spillover effects as a significant increase in the linkages across countries (or markets) after a shock in one country (or market), like a financial crisis. Interdependence is defined as strong linkages between two countries (or financial markets) that exist at all times, including the time before a financial crisis, but also during the crisis.

This paper aims to investigate interdependence effects of financial turbulence via different transmission channels in both the pre-crisis and the GFC periods, and spillover effects in the GFC period within one framework. Following Caprio and Klingebiel (1996) and Demirgüç-Kunt and Detragiache (1998), we apply the ratio of nonperforming loans to total gross loans as proxy for financial turbulence and use spatial econometric techniques to analyze propagation of financial turbulence.

This paper makes several contributions. Firstly, unlike most previous studies, we distinguish spillover and interdependence effects in analyzing financial turbulence propagation. This distinction is important since appropriate policy interventions may depend on the propagation mechanism at work. If financial turbulence is due to interdependence, trade diversification could be effective to reduce propagation of financial turbulence, while liquidity support or other forms of financial assistance are probably not very effective under these circumstances and may even delay appropriate adjustments. By contrast, if financial turbulence is due to spillover effects, like a freeze of the money market, liquidity support to stabilize the banking system could be more effective.

Secondly, for optimal policy interventions, it is also critical to identify the transmission channel of financial turbulence propagation. Research by Mendoza and Quadrini (2010) suggests that capital flows play an important role in the propagation of financial crises. However, also trade can transmit a crisis from one country to another (Calvo and Reinhart 1996). Moreover, Glick and Rose (1999) argue that crises occur regionally, suggesting that distance may also be important. The proposed spatial econometric 
model in this paper is estimated for each of the three mentioned transmission channels so as to be able to compare the impact of these different channels. The capital flows channel is measured by bank lending in one country to residents in other countries, while the trade channel is measured by exports and imports between countries. Finally, distance is calculated by the great circle distance between the capitals of countries.

Thirdly, we apply advanced spatial econometric techniques to investigate the propagation of financial turbulence. Propagation of financial turbulence may be characterized by spatial dependence, which is a special case of cross-sectional dependence, in the sense that the structure of the correlation or covariance between observations with different linkages is derived from a specific ordering, determined by the relative position of the observations in trade, capital flows, or geographic space. This definition of spatial dependence is similar to but broader than the definition given by Anselin (2006, p. 901) who only focuses on geographic space. A paper that comes close to ours is Triki and Maktouf (2012), who adopt a spatial Durbin model to investigate the relationship between financial liberalization and banking crises based on a sample of 40 emerging and developed countries during the 1989-2010 period. They find evidence that banking crises spread across countries. However, they neither distinguish between spillover and interdependence effects of banking crises nor do they investigate whether trade and financial channels play a role in banking crises propagation.

Although the point estimates of the variables in a spatial econometric model provide relevant information regarding the existence of interdependence and spillover effects, they do not provide any information on the marginal effects of the explanatory variables on the dependent variable. Kelejian et al. (2006) and LeSage and Pace (2009) point out that a partial derivative interpretation of the impact from changes in variables represents a more valid basis for determining this impact in a spatial econometric model. The formulas for this approach have been derived by LeSage and Pace (2009, p. 39) for a cross-sectional setting and by Elhorst (2014a) for a spatial panel data setting. However, to be able to apply this approach for the case that interdependence and spillover effects are considered within one framework, these formulas need to be generalized. By deriving what is known in the spatial econometrics literature as direct and indirect effect estimates, ${ }^{1}$ we show that the marginal effects of macroeconomic variables (like GDP growth, inflation, and credit growth) on financial turbulence take different forms during a crisis than in tranquil periods.

The setup of this paper is as follows. Section 2 reviews the literature on spillover effects and interdependence effects and on transmission channels. Section 3 sets out the spatial econometric model proposed and the definitions of interdependence, spillover, and direct and indirect effects as used in this study. Section 4 introduces the data, while Sect. 5 reports and discusses the estimation results and elaborates on the outcomes of different robustness tests. Finally, Sect. 6 concludes.

\footnotetext{
${ }^{1}$ In Kelejian et al. (2006), these direct and indirect effects are designated own contagion and emanating effects.
} 


\section{Literature review}

\subsection{Spillover effects and interdependence}

Forbes and Rigobon (2002) and Forbes (2012) define spillover effects as a significant increase in the linkages across financial markets after a shock in one country. Similarly, the World Bank ${ }^{2}$ talks about spillover effects "when cross-country correlations increase during crisis times relative to correlations during tranquil times." Forbes (2012) defines interdependence as a strong linkage between two financial markets during all periods. Therefore, based on these definitions, interdependence indicates a strong, structural relationship across countries or markets at all times, whereas spillover effects only emerge during a crisis and are temporary.

\subsection{Spillover channels}

In this paper, we focus on financial turbulence propagation through trade and capital flows. As some studies suggest that also distance plays a role in financial turbulence propagation, we take distance into account in our analysis as well.

\section{Trade linkage}

Trade can transfer financial turbulence through competition and bilateral trade. Corsetti et al. (2000) argue that competitors can be affected by each other. Suppose countries A and $\mathrm{B}$ export similar goods to country $\mathrm{C}$ and that a devaluation of country A's currency improves its competitive position, as a result of which country $\mathrm{C}$ will import more goods from $\mathrm{A}$ and less from $\mathrm{B}$. This change will create a balance-of-payments problem in country B. To regain equilibrium, country B has either to devalue its currency as well or to adjust through a recession (or employ a mix of both).

Likewise, Gerlach and Smets (1995) develop a model for two countries of which the first country has a depreciated currency against that of a third country. Consequently, its competitiveness improves, which affects the second country both directly (by lower exports) and indirectly (by higher imports at lower prices, which causes lower inflation), eventually resulting in a depreciation in the second country.

\section{Bank lending linkage}

After the Southeast Asian crisis in 1997, financial linkages were identified as a propagation channel of financial turbulence. Notably, banks and portfolio investors play an important role in crisis transmission (Kaminsky and Reinhart 2000; Forbes 2012). We focus on bank lending in transmitting financial turbulence, because bank lending can affect financial turbulence in the banking system more directly than other financial flows.

\footnotetext{
${ }^{2}$ See http://go.worldbank.org/JIBDRK3YC0.
} 
Financial turbulence can spread across countries in a similar way as in the trade channel (Kaminsky and Reinhart 2000). Suppose country C lends to countries A and $\mathrm{B}$ and that a major shock in country $\mathrm{A}$ increases the ratio of nonperforming loans of banks in country $\mathrm{C}$. To comply with bank regulations, banks in country $\mathrm{C}$ should either increase their capital positions or decrease their loans. If they choose to reduce outstanding loans, including those to country B, the banking sector in that country will be affected negatively.

Likewise, a crisis in the banks' home country may affect financial turbulence in other countries. During a crisis, the banking sector may face liquidity shortages and the market value of bank assets may decrease. If banks respond by re-balancing their portfolios, they prefer to reduce their foreign exposures and the volume of foreign bank claims (De Haas and Van Lelyveld 2014). Consequently, these countries face an increased probability of financial turbulence. Thus, financial turbulence in the banking system of one country may be transmitted to other countries, even if these countries have stable fundamentals and do not have strong trade relations with the country where the crisis originated.

\section{Distance}

Glick and Rose (1999) claim that currency crises tend to affect countries which are located nearby. Glick and Rose (1999, pp. 605-06) refer to the Asian, peso, and EMS crises and conclude that all three waves of attacks were largely regional phenomena. Once a country had suffered a speculative attack (Thailand in 1997, Mexico in 1994, Finland in 1992), its trading partners and competitors were disproportionately likely to be attacked. But this is not just reflecting trade relations, because not all major trading partners devalued or were attacked. Likewise, Kaminsky and Reinhart (2000) argue that banking crises tend to be regionally centered.

\subsection{Propagation of financial turbulence}

Up to now, only a few papers (which will be discussed in more detail below) studied the propagation of financial turbulence. In addition, these papers do not distinguish spillover and interdependence effects, but focus on spillover effects.

Van Rijckeghem and Weder (2003) investigate the role of bank lending in the financial crises of the 1990s using a sample of 30 emerging markets. Their results suggest that bank lending plays a significant role in crises propagation across countries. Similarly, Cetorelli and Goldberg (2010) conclude that global banks play a significant role in the transmission of the GFC from developed countries to emerging markets.

Santor (2003) examines the spillover effects of banking crises. His results show that spillover effects occur between countries that have a similar income level, rather than between countries that are located closely to each other. Tonzer (2015) applies a spatial econometric model to investigate the spillovers of banking crises among 15 developed countries over the period 1994-2012 and finds that interbank market lending is an important determinant of banking crises spillovers. Similar to Triki and Maktouf (2012), Tonzer (2015) does not distinguish between spillovers and interdependence. 
Dungey and Gajurel (2014) apply a multifactor model to investigate the contagion effects of banking crises from the USA to 54 countries. They find evidence of contagion effects across countries during the GFC. Likewise, Kali and Reyes (2010) investigate "financial contagion". They apply bilateral trade data in 182 countries over the period 1992-2000 and find evidence for this through a complex network of trade linkages. As financial contagion "involves changes in expectations that are not related to changes in a country's macroeconomic fundamentals" (Masson 1999, p. 267), Kali and Reyes (2010) basically analyze spillover effects.

One way to view contagion is as those propagation effects that cannot be covered by fundamentals and are thus part of the error term (see Dungey et al. 2005 for a further discussion of contagion). In the next section, we will demonstrate that while interdependence effects have a major impact on the direct and indirect effect estimates, contagion effects covered by the error term have not.

\section{Econometric model}

To account for spatial dependence among cross-sectional units such as countries, the spatial econometrics literature has developed linear regression models extended to include a spatially lagged dependent variable, spatially lagged explanatory or control variables, and/or a spatially lagged error term. The most popular spatial econometric models are the spatial lag model, the spatial error model, and the spatial Durbin model. The first model incorporates a spatially lagged dependent variable, the second model a spatially lagged error term, and the third model includes both a spatially lagged dependent variable and spatially lagged explanatory or control variables. LeSage and Pace (2009) demonstrate that the spatial lag and the spatial error model are special cases of the spatial Durbin model. For this reason, we employ the spatial Durbin model to study financial turbulence propagation. Details of spatial econometric models for spatial panels are provided in Elhorst (2014b). Conditions that need to be imposed on the spatial weight matrix, to be introduced shortly, such that the cross-sectional correlation among countries converges to zero as the distance separating them increases, were set out for the first time in Kelejian and Prucha $(1998,1999)$ for IV/GMM estimators and in Lee (2004) for ML estimators of the parameters of these models. Recent overviews of both estimation methods with respect to spatial econometric models are available in Prucha (2014) and Pace (2014).

The spatial Durbin model takes the form

$$
y_{i t}=\delta \sum_{j=1}^{N} w_{i j} y_{j t}+\boldsymbol{x}_{i t} \boldsymbol{\beta}+\left(\sum_{j=1}^{N} w_{i j} \boldsymbol{x}_{j t}\right) \boldsymbol{\theta}+\mu_{i}+\epsilon_{i t},
$$

where $y_{i t}$ is the dependent variable of country $i$ at time $t(i=1, \ldots, N ; t=1, \ldots, T)$. $\sum_{j} w_{i j} y_{j t}$ denotes the spatially lagged dependent variable reflecting the interdependence of country $i$ with the dependent variables of countries $j ; w_{i j}$ is the element of a predetermined nonnegative $N \times N$ spatial weight matrix $\boldsymbol{W}$ describing whether or not the country pairs $i$ and $j$ are interdependent, and if so the extent to which, while $\delta$ 
measures the impact of these spatially weighted dependent variables. Commonly, the diagonal elements $w_{i i}$ are set to zero since countries cannot be interdependent with themselves. $\boldsymbol{x}_{i t}$ is a $1 \times K$ row-vector of control variables, and $\sum_{j=1}^{N} w_{i j} \boldsymbol{x}_{j t}$ a vector of spatially lagged control variables representing the interdependence of country $i$ with the control variables of countries $j$, where it is assumed that the spatial weight matrix for the control variables is the same as for dependent variable; $\boldsymbol{\beta}$ and $\boldsymbol{\theta}$ are the corresponding $K \times 1$ vectors of coefficients. The symbol $\mu_{i}$ denotes country fixed effects which are meant to control for country-specific time-invariant variables that do affect the dependent variable, but which are difficult to measure or hard to obtain. Finally, $\boldsymbol{\epsilon}_{i t}$ is an independent and identically distributed error term for all $i$ and $t$ with zero mean and variance $\sigma^{2}$.

To capture potential spillovers due to a crisis, the basic spatial Durbin model is extended to contain interaction terms between the dependent variable and the control variables with a crisis dummy variable, which yields

$$
\begin{aligned}
y_{i t}= & \delta \sum_{j=1}^{N} w_{i j} y_{j t}+\eta d_{t} \sum_{j=1}^{N} w_{i j} y_{j t}+\boldsymbol{x}_{i t} \boldsymbol{\beta}+d_{t} \boldsymbol{x}_{i t} \zeta+\left(\sum_{j=1}^{N} w_{i j} \boldsymbol{x}_{j t}\right) \boldsymbol{\theta} \\
& +d_{t}\left(\sum_{j=1}^{N} w_{i j} \boldsymbol{x}_{j t}\right) \boldsymbol{\gamma}+\mu_{i}+d_{t} \alpha+\epsilon_{i t},
\end{aligned}
$$

where $d_{t}$ is a dummy variable which takes the value of 1 when period $t$ falls within a crisis period and 0 when not. The coefficients $\eta$ and $\alpha$, and the $K \times 1$ vectors of coefficients $\zeta$ and $\gamma$ measure the difference of, respectively, the intercept, the spatially lagged dependent variable, the control variables, and the spatially lagged control variables in the crisis period relative to the tranquil period and therefore capture spillover effects. For example, if the coefficient $\delta$ turns out to be significantly different from zero, this points to interdependence of financial turbulence across countries, whereas a similar outcome for $\eta$ provides empirical evidence in favor of spillover effects across countries. In this model, it is assumed that the explanatory variables and the spatial weight matrix are exogenous and that the latter does not change due to the existence of spillovers. A recent contribution dealing with endogenous explanatory variables is of Drukker et al. (2013), with an endogenous spatial weight matrix of Kelejian and Piras (2014), while a recent application to model the elements of the latter matrix by a gravity type of model is of Elhorst and Halleck Vega (2017). These relatively new approaches are interesting topics for further research. Time-period fixed effects are not included in Eqs. (1) and (2), but note that due to the addition of the crisis dummy $d_{t}$, the parameters in the tranquil and the crisis periods will be different. The intercept in the tranquil period can be calculated by $\frac{1}{N} \sum_{i=1}^{N} \mu_{i}$ and in the crisis period by $\sum_{i=1}^{N} \mu_{i}+\alpha$; the parameter $\alpha$ measures the difference between them. 
We estimate the spatial model in (2) by the method of maximum likelihood and apply likelihood ratio (LR) tests to investigate whether or not the country fixed effects are jointly significant by testing the hypothesis whether they can be replaced by one common intercept. ${ }^{3}$ We also apply LR tests to investigate whether the spatial Durbin model can be simplified to a spatial lag or spatial error model, by testing $H_{0}: \boldsymbol{\theta}=\boldsymbol{\gamma}=$ $\mathbf{0}$ and $H_{0}: \boldsymbol{\theta}+\delta \boldsymbol{\beta}=\boldsymbol{\gamma}+\eta \boldsymbol{\zeta}=\mathbf{0}$, respectively. If these hypotheses are rejected, we may conclude that the spatial Durbin model outperforms these simpler and somewhat more popular models in the spatial econometrics literature.

A remaining question is whether spatial dependence among the error terms should also be controlled for. Financial market shocks may be expected to affect loan repayment also through a shock of the error term, and this might subsequently propagate through the error terms of neighboring countries due to variables omitted from the model that these countries have in common. A model accounting for spatial dependence among the dependent variable, the explanatory variables, and the error term is known nowadays as a general nesting spatial model (Burridge et al. 2017). Estimating such a model is not straightforward, since it is not known whether the parameters are identified. This has only been proven for a group interaction matrix (Lee et al. 2010), but not for a general specification of the spatial weight matrix. Furthermore, even if the parameters are identified, one faces several empirical problems, such as overfitting (see Burridge et al. 2017). A Bayesian comparison approach has recently been developed by LeSage (2015) to discriminate between spatial dependence among the dependent variable and spatial dependence among the error terms, provided that spatial dependence among the explanatory variables is accounted for, but only for single lags, as in Eq. (1), and not for multiple lags, as in Eq. (2). We therefore leave this topic for further research.

Although the point estimates of the variables in the spatial Durbin model provide relevant information regarding the existence of interdependence and spillover effects, they do not provide any information on the marginal effects of the control variables on nonperforming loans, neither in the home country nor in other countries. To derive these marginal effects, the spatial Durbin model in (2) is rewritten, first in vector form by stacking each cross section of $N$ observations at time $t$ in the $N \times 1$ vector $\boldsymbol{Y}_{t}$ and the $N \times K$ vector $\boldsymbol{X}_{t}$, to get

$\boldsymbol{Y}_{t}=\delta \boldsymbol{W} \boldsymbol{Y}_{t}+\eta \boldsymbol{D}_{t} \boldsymbol{W} \boldsymbol{Y}_{t}+\boldsymbol{X}_{t} \boldsymbol{\beta}+\boldsymbol{D}_{t} \boldsymbol{X}_{t} \boldsymbol{\zeta}+\boldsymbol{W} \boldsymbol{X}_{t} \boldsymbol{\theta}+\boldsymbol{D}_{t} \boldsymbol{W} \boldsymbol{X}_{t} \boldsymbol{\gamma}+\boldsymbol{\mu}+\boldsymbol{D}_{t} \alpha+\boldsymbol{\epsilon}_{t}$,

where $\boldsymbol{D}_{t}$ is a diagonal matrix with ones on the diagonal if period $t$ falls within a crisis period and $\boldsymbol{\mu}=\left(\mu_{1}, \ldots, \mu_{N}\right)^{\prime}$, and then to its reduced form in (4),

$$
\begin{aligned}
\boldsymbol{Y}_{t}= & \left(\boldsymbol{I}_{N}-\delta \boldsymbol{W}-\eta \boldsymbol{D}_{t} \boldsymbol{W}\right)^{-1} \\
& \times\left(\boldsymbol{X}_{t} \boldsymbol{\beta}+\boldsymbol{D}_{t} \boldsymbol{X}_{t} \boldsymbol{\zeta}+\boldsymbol{W} \boldsymbol{X}_{t} \boldsymbol{\theta}+\boldsymbol{D}_{t} \boldsymbol{W} \boldsymbol{X}_{t} \boldsymbol{\gamma}+\boldsymbol{\mu}+\boldsymbol{D}_{t} \alpha+\boldsymbol{\epsilon}_{t}\right) .
\end{aligned}
$$

\footnotetext{
3 The MATLAB program for the estimations, for testing these hypotheses, and for determining the different types of effects considered in this study is adapted from programs available at the homepage of J. Paul Elhorst: http://www.regroningen.nl/elhorst/software.shtml. The adapted program is available on request.
} 
Taking partial derivatives of the expected value of $\boldsymbol{Y}_{t}$ with respect to the $k$ th control variable of $\boldsymbol{X}$ in country 1 up to country $N$ (say $\boldsymbol{x}_{i t, k}$ for $i=1, \ldots, N$, respectively) at a particular moment in time $t$ then yields the $N \times N$ matrix

$$
\begin{aligned}
& \left(\begin{array}{llll}
\frac{\partial E\left(\boldsymbol{Y}_{t}\right)}{\partial \boldsymbol{x}_{1 t, k}} & \cdots & \frac{\partial E\left(\boldsymbol{Y}_{t}\right)}{\partial \boldsymbol{x}_{N t, k}}
\end{array}\right)=\left(\begin{array}{ccc}
\frac{\partial E\left(\boldsymbol{y}_{1 t}\right)}{\partial \boldsymbol{x}_{1 t, k}} & \cdots & \frac{\partial E\left(\boldsymbol{y}_{1 t}\right)}{\partial \boldsymbol{x}_{N t, k}} \\
\vdots & \ddots & \vdots \\
\frac{\partial E\left(\boldsymbol{y}_{N t}\right)}{\partial \boldsymbol{x}_{1 t, k}} & \cdots & \frac{\partial E\left(\boldsymbol{y}_{N t}\right)}{\partial \boldsymbol{x}_{N t, k}}
\end{array}\right) \\
& =\left(\boldsymbol{I}_{N}-\delta \boldsymbol{W}-\eta \boldsymbol{D}_{t} \boldsymbol{W}\right)^{-1}\left(\begin{array}{cccc}
\beta_{k}+d_{t} \zeta_{k} & \theta_{k} w_{12}+d_{t} \gamma_{k} w_{12} & \ldots \theta_{k} w_{1 N}+d_{t} \gamma_{k} w_{1 N} \\
\theta_{k} w_{21}+d_{t} \gamma_{k} w_{21} & \beta_{k}+d_{t} \zeta_{k} & \ldots \theta_{k} w_{2 N}+d_{t} \gamma_{k} w_{2 N} \\
\vdots & \vdots & \ddots & \vdots \\
\theta_{k} w_{N 1}+d_{t} \gamma_{k} w_{N 1} & \theta_{k} w_{N 2}+d_{t} \gamma_{k} w_{N 2} & \ldots & \beta_{k}+d_{t} \zeta_{k}
\end{array}\right)
\end{aligned}
$$

where the subscript $k$ of $\boldsymbol{\beta}, \boldsymbol{\theta}, \boldsymbol{\zeta}$ and $\boldsymbol{\gamma}$ denotes the $k$ th element of these $K \times 1$ vectors of coefficients. The diagonal elements of this matrix expression represent the impact on the dependent variable of country 1 up to $N$ if the $k$ th control variable in the own country changes, and the off-diagonal elements if the $k$ th control variable in another country changes. ${ }^{4}$ Country fixed effects, as well as the error term, drop out due to taking the expectation of $\boldsymbol{Y}_{t}$. LeSage and Page (2009, pp. 34-39) define the direct effect as the average diagonal element of the full $N \times N$ matrix expression on the right-hand side of (5), ${ }^{5}$ and the indirect effect as the average row or column sums of the off-diagonal elements of that matrix. Normally, these marginal effects are independent of the time index $t$, provided that the spatial weight matrix does not change over time, but due to the crisis dummy $d_{t}$ the direct and indirect effects estimates in a crisis will be different from those in tranquil periods.

Unfortunately, the SE and $t$ values of the direct and indirect effects estimates are more difficult to determine. This is because they depend in a nonlinear way on $\beta_{k}$, $\theta_{k}, \delta$ and the elements of the spatial weights matrix $\boldsymbol{W}$ in the tranquil period, and in addition on $\zeta_{k}, \gamma_{k}$, and $\eta$ in a crisis. In order to draw inferences regarding the statistical significance of the direct and indirect effects during the tranquil period and their changes during a crisis, we therefore follow LeSage and Pace (2009, pp. 114115) who suggest simulating the distribution of the direct and indirect effects using the variance-covariance matrix implied by the maximum likelihood estimates. If the parameter vector $\boldsymbol{v}=\left(\delta, \boldsymbol{\beta}^{\prime}, \boldsymbol{\theta}^{\prime}\right)^{\prime}$ is drawn $D$ times from $N(\hat{\boldsymbol{v}}, \operatorname{Asy} \operatorname{Var}(\hat{\boldsymbol{v}}))$ in the tranquil period and a similar set of relevant parameters $\boldsymbol{\omega}=\left(\delta, \eta, \boldsymbol{\beta}^{\prime}, \boldsymbol{\theta}^{\prime}, \boldsymbol{\zeta}^{\prime}, \boldsymbol{\gamma}^{\prime}\right)^{\prime} D$ times in a crisis, the SD of each summary indicator can be approximated by the SD of the mean value over these $D$ draws in each period, and the significance by dividing each summary indicator by the corresponding estimated SD.

\footnotetext{
4 Since the diagonal elements $w_{i i}$ of the $N \times N$ matrix $W$ are set to zero, they do not show up on the diagonal of the second matrix on the right-hand side of (5).

5 Note that the full $N \times N$ matrix is the product of two $N \times N$ matrix. The elements of the first of these two matrices are not specified since their analytical expressions are unknown.
} 


\section{Data}

We collected annual data from 2003 to 2010 for 40 advanced, emerging, and developing countries, including 24 countries which suffered from a banking crisis since 2007 according to Laeven and Valencia (2013). More details are shown in Table 9 of the Appendix.

\subsection{Dependent variable}

Most previous studies on financial turbulence propagation use a dummy for banking crises as dependent variable, using information on variables such as closures, mergers, and government support (see Laeven and Valencia 2013 for details). However, the dichotomous nature of crisis dummies implies loss of information. For instance, before a crisis actually occurs, there is a buildup of risk that the crisis dummy will not pick up. Therefore, we use the ratio of nonperforming loans to total gross loans as dependent variable, following Caprio and Klingebiel (1996) and Demirgüç-Kunt and Detragiache (1998), who consider NPL a good indicator of financial turbulence in the banking system. The disadvantage of alternative variables, such as exchange rate depreciation, capital flow reversals, public debt, and asset prices, is that they are not proper indicators of turbulence in the banking sector, but capture turbulence on financial markets, which may or may not be related to turbulence in the banking sector. NPL data are obtained from the World Bank's World Development Indicators (Table 1).

We consider the subprime crisis, which occurred in the USA in 2007, as the shock which is propagated and the crisis period 2008-2010 as the post-shock period. Using Eq. (2), we estimate the spillover and interdependence effects within one framework.

Table 2 shows statistics for the NPL ratio in countries with a banking crisis and countries without a banking crisis over the whole observation period, and over the periods 2003-2007 and 2008-2010, to demonstrate that financial turbulence differs among these two types of countries and among these two periods. For countries with a banking crisis, the average NPL ratio increases from 0.031 in the pre-crisis period to 0.071 in the crisis period. In contrast, in countries without a banking crisis, the mean NPL ratio in 2003-2007 is higher than in 2008-2010. Five Asian countries,

Table 1 Nonperforming loans over total assets

\begin{tabular}{llll}
\hline Time & Mean & SD & Median \\
\hline 2003 & 0.053 & 0.059 & 0.031 \\
2004 & 0.047 & 0.058 & 0.027 \\
2005 & 0.034 & 0.039 & 0.019 \\
2006 & 0.030 & 0.034 & 0.019 \\
2007 & 0.025 & 0.026 & 0.017 \\
2008 & 0.032 & 0.028 & 0.028 \\
2009 & 0.069 & 0.096 & 0.036 \\
2010 & 0.059 & 0.074 & 0.037 \\
\hline
\end{tabular}


Table 2 NPL ratios in crisis and no-crisis countries and different periods

\begin{tabular}{lll}
\hline & Crisis countries & No-crisis countries \\
\hline 2003-2007 & & \\
Mean & 0.031 & 0.047 \\
SD & 0.046 & 0.044 \\
Median & 0.019 & 0.035 \\
2008-2010 & & \\
Mean & 0.071 & 0.027 \\
SD & 0.089 & 0.015 \\
Median & 0.036 & 0.024 \\
2003-2010 & & \\
Mean & 0.046 & 0.039 \\
SD & 0.068 & 0.037 \\
Median & 0.026 & 0.031 \\
\hline
\end{tabular}

namely China, India, Malaysia, Philippines, and Thailand, even have a monotonously decreasing NPL ratio during 2003-2010. This is in line with the finding of Shehzad and De Haan (2013) that the GFC was not really a global banking crisis. Stock prices of banks in emerging countries faced a temporary shock but quickly recovered, while stock prices of banks located in industrial countries remained much lower than before the crisis.

\subsection{Financial turbulence transmission channels}

We construct and employ three weight matrices. The first matrix is based on bilateral trade linkages $\left(\boldsymbol{W}^{\boldsymbol{T}}\right)$ using data on imports and exports between every pair of countries. The elements $w_{i j}^{T}$ of this matrix are constructed as follows:

$$
w_{i j}^{T}=\frac{1}{2}\left(\frac{t_{i j}}{t_{i}}+\frac{t_{j i}}{t_{j}}\right), \quad i, j=1, \ldots, N,
$$

where $t_{i j}$ is the sum of imports and exports from country $i$ to country $j$ recorded by country $i$, and $t_{i}\left(t_{j}\right)$ denotes the total imports and exports of country $i(j)$.

The elements $w_{i j}^{F}$ of the weight matrix based on banks' bilateral foreign claims on other countries $\left(\boldsymbol{W}^{\boldsymbol{F}}\right)$ are constructed as follows:

$$
w_{i j}^{F}=\frac{1}{2}\left(\frac{f_{i j}}{f_{i}}+\frac{f_{j i}}{f_{j}}\right), \quad i, j=1, \ldots, N,
$$

where $f_{i j}$ is the total foreign claims of banks in country $i$ on residents in country $j$, and $f_{i}\left(f_{j}\right)$ is the total foreign claims of banks in country $i(j)$ on residents of all countries. 
The distance weight matrix $\left(\boldsymbol{W}^{\boldsymbol{D}}\right.$ ) is based on the great circle distance between the capitals of country $i$ and $j$, which is calculated as follows:

$$
d_{i j}=\arccos \left[\left(\sin \phi_{i} \cdot \sin \phi_{j}\right)+\left(\cos \phi_{i} \cdot \cos \phi_{j} \cdot \cos (\Delta \tau)\right)\right] \cdot R,
$$

where $\phi_{i}$ and $\phi_{j}$ are the centroid's latitude of the capitals of country $i$ and $j$, respectively, and $\Delta \tau$ is the difference in longitude between these capitals. $R$ is the earth's radius of $6371 \mathrm{~km} .{ }^{6}$ The elements of the distance matrix are defined as:

$$
w_{i j}^{D}=\frac{1}{d_{i j}}, \quad i, j=1, \ldots, N,
$$

which implies that they increase if the capitals of two countries are closer located to each other, and vice versa.

Finally, the rows in each of these three matrices are normalized to sum to 1 , while their diagonal elements are set to zero. Data for the trade matrix are obtained from the International Monetary Fund (2010, Directions of Trade Statistics). Data for foreign claims are obtained from the Bank for International Settlements (BIS). Unfortunately, due to data availability, the sample used for analyzing the foreign claims channel only consists of 23 countries. The distance-based matrix is exogenous by definition. In constructing the trade and capital flow matrices, we use averages over the period 2003-2007 to avoid potential endogeneity problems. ${ }^{7}$

\subsection{Explanatory variables}

We select explanatory variables based on previous research on banking crises such as Demirgüç-Kunt and Detragiache (1998) and Klomp (2010). These variables include GDP growth, GDP per capita, inflation (measured by the change in the consumer price index), housing prices (real, growth rates), credit growth, private credit/GDP, M2/reserves, terms of trade, and trade openness. Adverse shocks affecting the economy, such as low growth, high inflation, rapid increases in housing prices, or a negative shock to the terms of trade, will reduce the solvency of borrowers and may therefore lead to an increase in nonperforming loans. As several studies have found that creditrelated variables, such as credit growth or private credit to GDP, have leading indicating properties of financial crises, we include those variables as well. As some studies suggest that banking sector problems may be related to foreign exchange reserves (Klomp 2010), we also take up the ratio of M2 to foreign exchange reserves. Following Klomp (2010), we further include GDP per capita to control for differences in economic

\footnotetext{
6 More details for this calculation can be found on the Web site http://www.movable-type.co.uk/scripts/ latlong.html.

7 We also constructed the trade and foreign claims weight matrices using average data from 2000 to 2002. For each channel, the correlation between these two matrices appeared to be lower than 0.3 , indicating that there is a substantial difference between the linkages among countries in different periods; for this reason, we chose matrices based on 2003-2007 figures.
} 
development. Finally, we consider housing prices as a bursting housing market bubble can cause an increase in nonperforming loans.

Table 10 in the Appendix provides more details on our variables and their data sources, while Table 3 reports summary statistics for the control variables in different periods. During tranquil periods, the mean and median GDP growth rates $(0.042$ and 0.038 , respectively) are higher while the SD of GDP growth is lower than during the crisis period. Similar differences between the two periods can also be found for other variables. The high maximum value for the M2/reserves ratio reflects Luxembourg's large financial sector.

\section{Empirical results}

Our sample contains 40 countries (except for our analysis of the foreign claims channel as pointed out above). The crisis period lasts 3 years. Each explanatory variable $X_{k}$ enters the spatial Durbin model four times: as explanatory variable in its original form $\left(X_{k}\right)$, as interaction effect of the explanatory variable with the crisis dummy $\left(d_{t} X_{k}\right)$, as spatially lagged explanatory variable observed in neighboring countries $\left(W X_{k}\right)$, and as interaction effect of the spatially lagged explanatory variable with the crisis dummy $\left(d_{t} W X_{k}\right)$. Therefore, the sample may be not large enough to include all $k$ explanatory variables at the same time.

Demirgüç-Kunt and Detragiache (1998) argue that banking crises tend to occur when the economic fundamentals are weak, particularly when GDP growth is low and inflation is high. Klomp (2010) highlights that low GDP growth and high credit growth are the most important leading indicators of banking crises. We therefore include GDP growth, inflation and domestic credit growth in our base model and subsequently add other control variables one by one to investigate the robustness of our results.

Table 4 shows model selection test results. First, we examine whether the country fixed effects are jointly significant or can be replaced by one common intercept. The values of the likelihood ratio (LR) test shown in the first row in Table 4 suggest that the country fixed effects have to be included in all three channels. Results of the LR tests shown in the second row and third row in Table 4 indicate that the null hypotheses whether the spatial Durbin model can be simplified to the spatial lag model or to the spatial error model are rejected at the $1 \%$ significant level. Therefore, we adopt the spatial Durbin model with country fixed effects in all our estimations.

Table 5 reports the basic results of the spatial Durbin model extended to include potential spillovers due to the GFC for all three channels. Since only 23 countries have capital flows data, the number of observations for the capital flows channel is 164; for the trade and distance channels, we have 320 observations. The R-squared values are higher than 0.67 , while the $\sigma^{2}$ values are small in all three specifications, indicating that they provide acceptable explanations of financial turbulence during the GFC. The calculation of the R-squared values includes the contribution of the spatial lags in $Y$ ( $\boldsymbol{W} \boldsymbol{Y}_{t}$ and $\boldsymbol{D}_{t} \boldsymbol{W} \boldsymbol{Y}_{t}$ ), and of the country fixed effects (see Elhorst 2014b, Section 3.5.1 for details). Since the parameter estimates of the extended spatial Durbin model for the three transmission channels are based on different numbers of observations, the loglikelihood values are incomparable. For this reason, we also estimated the extended 


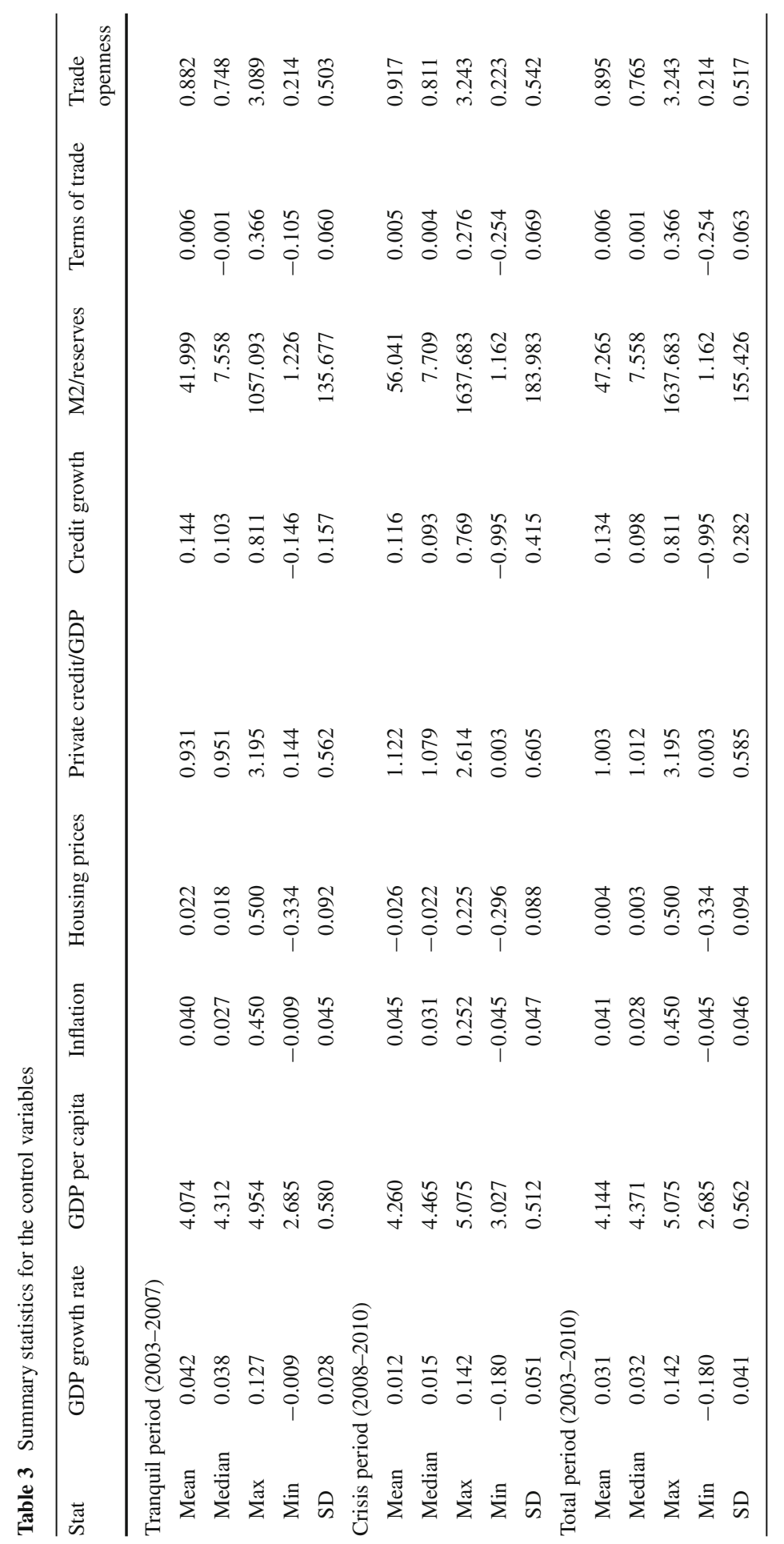


Table 4 Test results for different spatial model specifications

\begin{tabular}{|c|c|c|c|c|c|c|}
\hline & \multicolumn{2}{|c|}{ Capital flow channel } & \multicolumn{2}{|c|}{ Trade channel } & \multicolumn{2}{|c|}{ Distance channel } \\
\hline & t-stat & $p$ value & t-stat & $p$ value & t-stat & $p$ value \\
\hline LR fixed effects & $181.509 * * *$ & 0.000 & $211.039 * *$ & 0.000 & $211.039 * * *$ & 0.000 \\
\hline LR spatial lag & $10.383 * * *$ & 0.001 & $35.122 * * *$ & 0.000 & $11.106^{* * *}$ & 0.001 \\
\hline LR spatial error & $6.197 * *$ & 0.013 & $22.525 * * *$ & 0.000 & $9.576 * * *$ & 0.002 \\
\hline
\end{tabular}

$* * *, * *$, and $*$ denote significance at the 1,5 , and $10 \%$ levels, respectively

spatial Durbin model for the trade and distance channels on the same set of observations as for the capital flows channels. The log-likelihood values of the estimates based on 164 observations are also reported in Table 5. Since the log-likelihood function value of the capital flows channel is by far the largest of these three channels, 594.492 versus 520.075 and 522.476, it may be concluded that the capital flows channel gives the best model fit.

\section{Interdependence}

Rows 3-4 in Table 5 show our results for the spread of financial turbulence. We find evidence in favor of interdependence effects along the spatially lagged dependent variable $(W \times \mathrm{NPL})$ through the trade and distance channels, but not for the capital flows channel. There is also no evidence in support of spillover effects $(W \times$ NPL $\times D_{t}$ ) along any of these three channels.

Rows 5-10 in Table 5 show the impact of the macroeconomic explanatory variables on domestic and foreign banking systems during the tranquil period, and Table 6 reports the corresponding direct and indirect effects, based on expression (5) for $d_{t}=0$. The results in rows 5-7 of Table 5 and rows 1-3 of Table 6 show that the difference in size and significance between the point estimates and the direct effects are generally small. For example, the point estimate of inflation via the capital flows channel appears to be 0.163 and its direct effect to be 0.161 , reflecting a $1.2 \%$ difference. But there are some notable exceptions. For instance, the difference between the point estimate of inflation and its direct effect increases up to $21.46 \%$ (0.161 vs. 0.205$)$ for the distance channel and to $34.26 \%(0.142$ vs. 0.216$)$ for the trade channel. This difference between the point estimate and the direct effect is due to a loop of successive interdependence effects, i.e., impacts passing through the dependent variables of neighboring countries based on the nonzero elements in the $W$ matrix and back to the country that instigated the inflation change (e.g., A-B-A or A-B-C-A). Apparently, these interdependence effects are much larger for the distance and trade transmission channels than for the capital flows channel. Consequently, the point estimates may underestimate the impact of the macroeconomic variables, so that one better uses the direct effects reported in Table 6 for further interpretation. In the tranquil period, these direct effects are solely due to interdependence effects in the dependent variable measured by $\delta$ and the explanatory variables measured by $\theta$. 
Table 5 Estimation results (dependent variable: NPL)

\begin{tabular}{|c|c|c|c|c|c|c|}
\hline & \multicolumn{2}{|c|}{ Capital flow channel } & \multicolumn{2}{|c|}{ Trade channel } & \multicolumn{2}{|c|}{ Distance channel } \\
\hline & Coefficient & t-stat & Coefficient & t-stat & Coefficient & t-stat \\
\hline Intercept & 0.023 & & -0.031 & & -0.013 & \\
\hline$D_{t}$ & $-0.017 *$ & -1.651 & $0.030 * *$ & 2.068 & 0.033 & 1.403 \\
\hline$W \times \mathrm{NPL}$ & 0.071 & 0.426 & $0.597 * * *$ & 6.225 & $0.562 * * *$ & 4.948 \\
\hline$W \times \mathrm{NPL} \times D_{t}$ & -0.373 & -1.574 & -0.164 & -0.977 & -0.087 & -0.459 \\
\hline GDP growth & $-0.156 *$ & -1.868 & $0.300 * *$ & 2.017 & $0.307 * *$ & 1.968 \\
\hline Inflation & $0.163^{* * *}$ & 5.658 & $0.142 * *$ & 2.016 & $0.161 * *$ & 2.213 \\
\hline Credit growth & $-0.090 * * *$ & -3.816 & $-0.102 * * *$ & -4.367 & $-0.092 * * *$ & -3.770 \\
\hline$W \times$ GDP growth & -0.098 & -0.522 & 0.273 & 0.762 & -0.304 & -0.734 \\
\hline$W \times$ Inflation & -0.005 & -0.096 & $0.877 * * *$ & 2.823 & 0.811 & 1.479 \\
\hline$W \times$ Credit growth & 0.045 & 0.818 & -0.005 & -0.065 & 0.063 & 0.624 \\
\hline GDP growth $\times D_{t}$ & -0.152 & -1.318 & $-0.551 * * *$ & -3.392 & $-0.741 * * *$ & -4.318 \\
\hline Inflation $\times D_{t}$ & $-0.177 * *$ & -2.059 & $0.627 * * *$ & 5.221 & $0.618 * * *$ & 5.633 \\
\hline Credit growth $\times D_{t}$ & 0.048 & 1.615 & $0.102 * * *$ & 4.362 & $0.092 * * *$ & 3.768 \\
\hline$W \times$ GDP growth $\times D_{t}$ & 0.009 & 0.040 & -0.416 & -1.063 & 0.515 & 1.151 \\
\hline$W \times$ Inflation $\times D_{t}$ & $0.677 * * *$ & 4.574 & $-0.947 * * *$ & -2.734 & $-1.464 * *$ & -2.536 \\
\hline$W \times$ Credit growth $\times D_{t}$ & 0.022 & 0.199 & 0.005 & 0.060 & -0.062 & -0.616 \\
\hline \# obs. & 164 & & 320 & & 320 & \\
\hline R-squared & 0.776 & & 0.695 & & 0.675 & \\
\hline$\sigma^{2}$ & 0.001 & & 0.001 & & 0.001 & \\
\hline Log-likelihood & 594.492 & & 644.672 & & 636.285 & \\
\hline Log-likelihood (164 obs.) & & & 520.075 & & 522.576 & \\
\hline
\end{tabular}

This table shows the estimation results for the spatial Durbin model based on the period 2003-2010 The dummy variable $d_{t}$ is equal to one for the period 2008-2010, and zero otherwise $* * *, * *$, and $*$ denote significance at the 1,5 and $10 \%$ levels, respectively

Table 6 Direct and indirect effects in levels during the tranquil period

\begin{tabular}{|c|c|c|c|c|c|c|}
\hline & \multicolumn{2}{|c|}{ Capital flow channel } & \multicolumn{2}{|c|}{ Trade channel } & \multicolumn{2}{|c|}{ Distance channel } \\
\hline & Estimate & t-stat & Estimate & t-stat & Estimate & t-stat \\
\hline \multicolumn{7}{|l|}{ Direct effects } \\
\hline GDP growth & $-0.160 *$ & -1.921 & $0.334 * *$ & 2.201 & $0.296^{*}$ & 1.839 \\
\hline Inflation & $0.161 * * *$ & 5.384 & $0.216 * * *$ & 2.638 & $0.205^{* *}$ & 2.442 \\
\hline Credit growth & $-0.087 * * *$ & -3.697 & $-0.107 * * *$ & -4.310 & $-0.090 * * *$ & -3.543 \\
\hline \multicolumn{7}{|l|}{ Indirect effects } \\
\hline GDP growth & -0.119 & -0.549 & 1.108 & 1.084 & -0.329 & -0.343 \\
\hline Inflation & 0.006 & 0.111 & $2.431 * *$ & 2.126 & 2.141 & 1.464 \\
\hline Credit growth & 0.039 & 0.630 & -0.165 & -0.767 & 0.037 & 0.150 \\
\hline
\end{tabular}

$* * *, * *$, and $*$ denote significance at the 1,5 , and $10 \%$ levels, respectively 
The interdependence effects for the macroeconomic variables observed in other countries, reported in rows $8-10$ of Table 5 , and the indirect effects to other countries, reported in rows 4-6 of Table 6 , are insignificant in the tranquil period, with one exception. It is generally harder to find empirical evidence in favor of significant indirect effects than in favor of significant interdependence effects. This is because the former depend on three parameters $\left(\delta, \beta_{k}, \theta_{k}\right)$, of which the latter two parameters correspond to interdependence effects. If already one of these three parameters happens to be insignificant, the indirect effect is likely to become insignificant too. The exception is the indirect effect of changes in the inflation rate in foreign countries along the trade channel. The point estimate of this control variable when adopting the trade transmission channel appears to be $\beta_{k}=0.142$ ( $t$ value 2.106), the interdependence effect of this control variable to be $\theta_{k}=0.877$ ( $t$ value 2.823), and the interdependence effect of the dependent variable (NPL) with the dependent variable of other countries to be $\delta=$ 0.597 ( $t$ value 6.225); hence the indirect effect of the inflation rate in foreign countries on the ratio of nonperforming loans within the focal country takes the value of 2.431 ( $t$ value 2.126). It should be stressed that this value needs to be interpreted with caution, since it reflects the impact of a $1 \%$ point increase of inflation in all foreign countries to which the focal country is linked according to the trade transmission channel. Since the average effect of the most influential country to which each focal country is linked according to the trade transmission channel equals 0.1869 , this implies that the ratio of nonperforming loans increases by $2.431 \times 0.1869=0.4544$ if the inflation rate in only the most influential country increases by $1 \%$ point.

\section{Spillovers}

Table 5 shows that 2 to 4 spillover effects, i.e., interaction effects between the crisis dummy and the control variables (the intercept reported in row 2 is included in this counting), turn out to be significantly different from zero, where the outcome of 2 refers to the capital flows channel and that of 4 to the trade channel. These numbers corroborate the need to differentiate the intercepts and slope coefficients in a crisis from those in tranquil periods so as to account for spillover effects and to improve model fit. In addition, 1 to 3 interdependence effects or interaction effects between the crisis dummy and the interdependence effects appear to be significantly different from zero, where the outcome of 1 refers to the capital flows channel and that of 3 to the trade channel. Although this latter number of significant interdependence effects is lower than the number of significant spillover effects, these results provide empirical evidence in favor of the proposition of this paper that spillover and interdependence effects should be modeled within one framework.

Row 4 of Table 5 shows that due to spillovers, the degree of interdependence of each country with the dependent variable of other countries falls for all transmission channels, by 0.373 for the capital flows channel, by 0.087 for the distance channel, and by 0.164 for the trade channel, although neither of these changes appears to be significant. Similarly, the direct impact of a $1 \%$ point increase in GDP growth falls substantially, from -0.160 (row 1 of Table 6) to -0.312 (row 1 of Table 7) for the capital flows channel, from 0.334 to -0.256 for the trade channel, and from 0.296 
Table 7 Direct and indirect effects in levels during the crisis period

\begin{tabular}{|c|c|c|c|c|c|c|}
\hline & \multicolumn{2}{|c|}{ Capital flow channel } & \multicolumn{2}{|c|}{ Trade channel } & \multicolumn{2}{|c|}{ Distance channel } \\
\hline & Estimate & t-stat & Estimate & t-stat & Estimate & t-stat \\
\hline \multicolumn{7}{|l|}{ Direct effects } \\
\hline GDP growth & $-0.312 * * *$ & -3.947 & $-0.256^{* *}$ & -2.287 & $-0.434 * * *$ & -4.002 \\
\hline Inflation & -0.034 & -0.357 & $0.785 * * *$ & 6.943 & $0.769 * * *$ & 7.001 \\
\hline Credit growth & $-0.044 *$ & -1.949 & -0.000 & -1.075 & -0.000 & -0.163 \\
\hline \multicolumn{7}{|l|}{ Indirect effects } \\
\hline GDP & 0.004 & 0.045 & $-0.436 * *$ & -1.996 & 0.060 & 0.078 \\
\hline Inflation & $0.540 * * *$ & 4.299 & 0.463 & 1.112 & -0.696 & -0.371 \\
\hline Credit growth & 0.067 & 0.829 & -0.008 & -0.657 & 0.002 & 0.463 \\
\hline
\end{tabular}

$* * *, * *$, and $*$ denote significance at the 1,5 and $10 \%$ levels, respectively

to -0.434 for the distance channel. Moreover, all these direct effects of GDP growth appear to be significant in the crisis period. These results indicate that temporary (negative) spillover effects of the GDP growth variable in the crisis period have a tremendous effect on its overall impact on financial turbulence and that a recovery of the national economy in terms of GDP growth is an important condition for reducing financial turbulence within that economy.

Reducing inflation is another measure that may help to reduce financial turbulence, although the different transmission channels throw a different light on the countries where inflation needs to be reduced. Starting from Table 6, the direct effect of reducing inflation domestically by $1 \%$ point in the tranquil period ranges from 0.161 for the capital flows channel, to 0.205 for the distance channel, and to 0.216 for the trade channel, and so appears to be quite similar for the different transmission channels. By contrast, whereas the indirect effect of reducing inflation in foreign countries has almost no effect according to the capital flows channel, this effect amounts to a positive and significant value of 2.431 for the trade channel and an almost similar but insignificant value of 2.141 for the distance channel. Converted to the average effect of the most influential foreign country, these numbers become 0.454 for the trade channel (multiplication by 0.1869 ) and 0.259 for the distance channel (multiplication by 0.1211$)$.

In the crisis period, the benefits of reducing inflation domestically increase significantly according to the latter two transmission channels, from 0.216 to 0.769 for the trade channel and from 0.205 (row 2 of Table 6) to 0.779 (row 2 of Table 7) for the distance channel, whereas this effect becomes almost zero for the capital flows channel. By contrast, the indirect effect of reducing inflation in foreign countries increases from a small and insignificant value of 0.006 (row 5 of Table 6) to a substantial and significant value of 0.540 (row 5 of Table 7) according to the capital flows channel, which represents the transmission channel with the best model fit, while an almost similar but insignificant number of 0.463 is obtained for the trade channel. In sum, although the results for the different transmission channels are mixed, they suggest that reducing inflation both in the own country and in foreign countries to which a 
country is linked, both in tranquil periods and during a crisis, may help to reduce financial turbulence.

Finally, the direct effect of credit growth reduction by $1 \%$ point ranges from a significant value of -0.087 for the capital flows channel to a significant value of -0.107 for the trade channel in tranquil periods. So these effects are rather similar and provide empirical evidence that an effective credit growth policy may help to reduce financial turbulence under normal economic circumstances. However, these direct effects become almost zero during a crisis period. Only the direct effect of -0.044 for the capital flows channel remains weakly significant, even though it is almost halved. In addition, the indirect effects of credit growth in foreign countries appear to be insignificant in all cases. These findings indicate that credit growth policy measures have no or hardly any effect during a crisis period.

\section{Robustness checks}

To investigate whether the model may or should be extended with more explanatory variables, we carried out a series of robustness checks by including, respectively, GDP per capita, private credit/GDP, M2/reserves, housing prices, terms of trade or trade openness. Most of these variables have limited relevance, except for M2/reserves and housing prices. Three out of the four M2/reserves variables in the spatial Durbin model when entering this additional explanatory variable appeared to be significant, independent of the transmission channel being considered. For housing prices, the significance differs across the transmission channel. In the spatial econometric model based on capital flows, three out of four variables appeared to be significant, two out of four with the trade channel, and one with the distance channel.

Since the capital flows channel appeared to give the best model fit, Table 8 reports the direct and indirect effects estimates of these model extensions for the capital flows transmission channel. ${ }^{8}$ The direct effect of $\mathrm{M} 2 /$ reserves during tranquil periods turns out to be small and insignificant, but its indirect effect amounts to a significant value of -0.023 . This implies that a $1 \%$ point increase of the most influential foreign country (multiplication by 0.2539 ) reduces NPLs by 0.006 percentage points. In the crisis period, this direct effect increases to a weakly significant value of -0.003 and its indirect effect to a value of -0.035 , which is significantly different from zero. The outcomes for housing prices are listed in the final four columns of the table. The direct effects of housing prices are significantly negative, -0.075 , in the tranquil period, but increase significantly to a value of 0.152 during the crisis period. Indirect effects are insignificant in the tranquil period, but decrease to a weakly significant value of -0.226 during the crisis. These outcomes again underline the importance of controlling for interaction effects between interdependence effects and the crisis dummy.

\footnotetext{
${ }^{8}$ Detailed results of all these robustness checks for every variable and every transmission channel are available on request.
} 


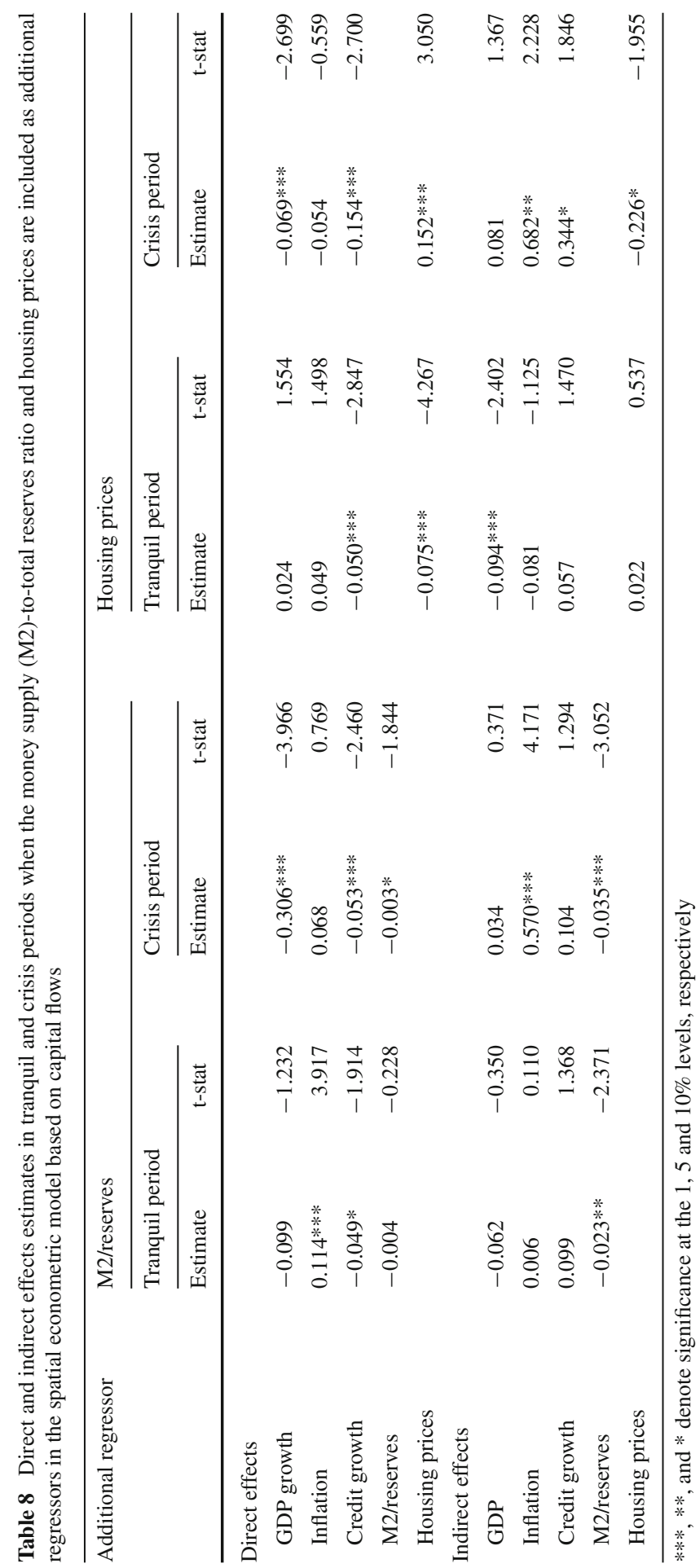




\section{Conclusion}

This paper demonstrates that interdependence and spillover effects of financial turbulence across countries during tranquil and crisis periods should be modeled within one model. The model used for this purpose is a spatial Durbin model. This is a linear regression model first extended to include a spatially lagged dependent variable and spatially lagged control variables reflecting the interdependence of each country with, respectively, the dependent variable and the explanatory variables observed in other countries, and then extended to include spillover effects, i.e., an additional set of interaction effects between the regressors already in the model and a crisis dummy with different slope coefficients. Since part of these interdependence effects, part of these spillover effects, among which interaction effects between the interdependence effects and the crisis dummy, appear to be significant, these effects cannot be separated from each other.

The model is estimated using annual data of 40 countries from 2003 to 2010. Although the point estimates of the variables in our spatial econometric model provide relevant information regarding the existence of interdependence and spillover effects, an important lesson from the spatial econometrics literature is that they do not provide any information on the marginal effects of these variables. By deriving marginal effects, known in the spatial econometrics literature as direct and indirect effects estimates, it is found that they take different values in tranquil periods than during a crisis. Furthermore, by comparing the point estimates of the control variables observed in the own country with the corresponding direct effects estimates, it is found that one better uses these direct effects estimates since the point estimates underestimate the domestic impact of the control variables due to a loop of successive interdependence effects of each country with other countries along the dependent variable. These underestimations may increase up to $35 \%$.

Since different studies propose different specifications of the transmission channels across countries, the spatial Durbin model extended to include spillover effects is estimated for three channels: (1) the trade channel, measured by exports and imports between countries; (2) the capital flows channel, measured by bank lending in one country to residents in other countries; and (3) distance, calculated by the great circle distance between the capitals of countries. The best model fit is obtained for the capitals flow channel. This study reports and discusses the results obtained for every channel, first to be able to compare the results, and second because the number of observations available for the estimation of the model based on the capital flows channel is smaller. Most results appear to be similar, but some are different.

We find that a recovery of the national economy in terms of GDP growth, especially in crisis periods, is an important condition for reducing financial turbulence as proxied by the ratio of nonperforming loans of banks within an economy. The impact of a $1 \%$ point increase in GDP growth ranges from -0.312 for the capital flows channel, to -0.256 for the trade channel, and -0.434 for the distance channel. Reducing inflation both in the own country and in foreign countries, both in tranquil periods and during a crisis, also reduces financial turbulence. The impact ranges from approximately 0.2 in tranquil periods to 0.8 during a crisis due to a domestic reduction of $1 \%$ point, and from approximately 0.1 in crisis periods to 0.5 due to an inflation reduction of $1 \%$ 
point in the most influential foreign country. Finally, we find that credit growth policy measures have no or hardly any effect during a crisis, and that the domestic effect of credit growth reduction by $1 \%$ point in tranquil periods ranges from -0.087 for the capital flows channel, to -0.090 for the distance channel, and -0.107 for the trade channel.

Open Access This article is distributed under the terms of the Creative Commons Attribution 4.0 International License (http://creativecommons.org/licenses/by/4.0/), which permits unrestricted use, distribution, and reproduction in any medium, provided you give appropriate credit to the original author(s) and the source, provide a link to the Creative Commons license, and indicate if changes were made.

\section{Appendix}

Table 9 Countries in the sample

Countries experiencing a banking crisis

\begin{tabular}{ll}
\hline Austria & Luxembourg \\
Belgium & Mongolia \\
Denmark & the Netherlands \\
France & Portugal \\
Germany & Russian \\
Greece & Slovenia \\
Hungary & Spain \\
Iceland & Sweden \\
Ireland & Switzerland \\
Italy & Ukraine \\
Kazakhstan & UK \\
Latvia & USA \\
\hline
\end{tabular}

Countries without a banking crisis

\begin{tabular}{ll} 
Australia & Japan \\
Brazil & Korea \\
Canada & Malaysia \\
China & Mexico \\
Czech Republic & New Zealand \\
Finland & Philippines \\
India & Thailand \\
Indonesia & Turkey \\
\hline
\end{tabular}

This table shows the list of countries in our sample. Banking crises events are taken from Laeven and Valencia (2013) 
Table 10 Variable description and sources

Sources

\begin{tabular}{ll}
$\begin{array}{l}\text { Dependent variable } \\
\text { Nonperforming loans/total gross loans }\end{array}$ & \\
Control variable & World Development Indicators \\
GDP growth rate & World Development Indicators \\
GDP per capita & World Development Indicators \\
Inflation & World Development Indicators \\
Private credit/GDP & World Development Indicators \\
Credit growth rate & World Development Indicators \\
Housing prices (real, growth rates) & BIS Statistics and CEIC \\
M2/reserves & World Development Indicators \\
Terms of trade & World Development Indicators \\
Trade openness & World Development Indicators \\
\hline
\end{tabular}

\section{References}

Aloui R, Aïssa MSB, Nguyen DK (2011) Global financial crisis, extreme interdependences, and contagion effects: the role of economic structure? J Bank Finance 35:130-141

Anselin L (2006) Spatial econometrics. In: Mills TC, Patterson K (eds) Palgrave handbook of econometrics. Terence Palgrave McMillan, Basingstoke, pp 901-969

Burridge P, Elhorst JP, Zigova K (2017) Group interaction in research and the use of general nesting spatial models. In: Baltagi BH, LeSage JP, Pace RK (eds) Spatial econometrics: qualitative and limited dependent variables (Advances in econometrics, Volume 37). Emerald Group Publishing Limited, Bingley, pp 223-258

Calvo S, Reinhart CM (1996) Capital flows to Latin America: is there evidence of contagion effects?. World Bank, Washington (World Bank Policy Research Working Paper 96/1619)

Caprio G, Klingebiel D (1996) Bank insolvencies: cross-country experience. World Bank, Washington (World Bank Policy Research Working Paper 96/1620)

Cetorelli N, Goldberg LS (2010) Global banks and international shock transmission: evidence from the crisis. IMF Econ Rev 59:41-76

Corsetti G, Pesenti P, Roubini N, Tille C (2000) Competitive devaluations: toward a welfare-based approach. J Int Econ 51:217-241

De Haas R, Van Lelyveld I (2014) Multinational banks and the global financial crisis: weathering the perfect storm? J Money Credit Bank 46:333-364

Demirgüç-Kunt A, Detragiache E (1998) The determinants of banking crises in developing and developed countries. IMF Staff Pap 45:81-109

Drukker DM, Egger P, Prucha IR (2013) On two-step estimation of a spatial autoregressive model with autoregressive disturbances and endogenous regressors. Econ Rev 32:686-733

Dungey M, Gajurel D (2014) Equity market contagion during the global financial crisis: evidence from the world's eight largest economies. Econ Syst 38:161-177

Dungey M, Fry R, González-Hermosillo B, Martin VL (2005) Empirical modelling of contagion: a review of methodologies. Quant Finance 5:9-24

Elhorst JP (2014a) Matlab software for spatial panels. Int Reg Sci Rev 37:389-405

Elhorst JP (2014b) Spatial econometrics: from cross-sectional data to spatial panels. Springer, Berlin

Elhorst JP, Halleck Vega S (2017) The SLX model: extensions and the sensitivity of spatial spillovers to W. Papeles de Economía Española, 152 (Forthcoming)

Forbes KJ (2012) The Big C: identifying contagion. National Bureau of Economic Research, Cambridge (NBER Working Paper 12/18465) 
Forbes KJ, Rigobon R (2002) No contagion, only interdependence: measuring stock market comovements. J Finance 57:2223-2261

Gerlach S, Smets F (1995) Contagious speculative attacks. Eur J Polit Econ 11:45-63

Glick R, Rose AK (1999) Contagion and trade: why are currency crises regional? J Int Money Finance 18:603-617

Kali R, Reyes J (2010) Financial contagion on the international trade network. Econ Inq 48:1072-1101

Kaminsky GL, Reinhart CM (2000) On crises, contagion, and confusion. J Int Econ 51:145-168

Kelejian HH, Piras G (2014) Estimation of spatial models with endogenous weighting matrices, and an application to a demand model for cigarettes. Reg Sci Urban Econ 46:140-149

Kelejian HH, Prucha IR (1998) A generalized spatial two stage least squares procedure for estimating a spatial autoregressive model with autoregressive disturbances. J Real Estate Finance Econ 17:99-121

Kelejian HH, Prucha IR (1999) A generalized moments estimator for the autoregressive parameter in a spatial model. Int Econ Rev 49:509-533

Kelejian HH, Tavlas GS, Hondroyiannis G (2006) A spatial modelling approach to contagion among emerging economies. Open Econ Rev 17:423-441

Klomp J (2010) Causes of banking crises revisited. North Am J Econ Finance 21:72-87

Laeven L, Valencia F (2013) Systemic banking crises database. IMF Econ Rev 61:225-270

Lee Lf (2004) Asymptotic distribution of quasi-maximum likelihood estimators for spatial autoregressive models. Econometrica 72:1899-1925

Lee Lf, Liu X, Lin X (2010) Specification and estimation of social interaction models with network structures. Econ J 13:145-176

LeSage JP (2015) Software for Bayesian cross section and panel spatial model comparison. J Geogr Syst 17:297-310

LeSage JP, Pace RK (2009) Introduction to spatial econometrics. CRC Press Taylor and Francis Group, Boca Raton

Masson P (1999) Contagion: macroeconomic models with multiple equilibria. J Int Money Finance 18:587602

Mendoza EG, Quadrini V (2010) Financial globalization, financial crises and contagion. J Monet Econ 57:24-39

Pace RK (2014) Maximum likelihood estimation. In: Fischer MM, Nijkamp P (eds) Handbook of regional science. Springer, Berlin, pp 1553-1569

Prucha IR (2014) Instrumental variables/method of moments estimation. In: Fischer MM, Nijkamp P (eds) Handbook of regional science. Springer, Berlin, pp 1597-1617

Santor E (2003) Banking crises and contagion: empirical evidence. Bank of Canada, Ottawa (Bank of Canada Working Paper 03/01)

Shehzad CT, De Haan J (2013) Was the 2007 crisis really a global banking crisis? North Am J Econ Finance 24:113-124

Tonzer L (2015) Cross-border interbank networks, banking risk and contagion. J Financial Stab 18:19-32

Triki MB, Maktouf S (2012) Financial liberalization and banking crisis: a spatial panel model. J Appl Finance Bank 2:81-122

Van Rijckeghem C, Weder B (2003) Spillovers through banking centers: a panel data analysis of bank flows. J Int Money Finance 22:483-509 